\title{
Value Null Flavor
}

National Cancer Institute

\section{Source}

National Cancer Institute. Value Null Flavor. NCI Thesaurus. Code C117374.

A description of the value that describes missing data, eg. unknown, not applicable. 